\title{
Teaching Guidance in Programming Courses from Procedure-oriented to Object-oriented
}

\author{
Yanmei Liu ${ }^{1}$ Min Sun ${ }^{1}$ \\ ${ }^{1}$ Wuhan Institute of Design and Sciences \\ Wuhan, China \\ 61704088@qq.com \\ 694593072@qq.com
}

\author{
Yuda Chen ${ }^{23}$ \\ ${ }^{2}$ National Engineering Research Center for Geographic \\ Information System \\ ${ }^{3}$ Wuhan center of Geological Survey \\ Wuhan, China \\ chyd555@163.com
}

\begin{abstract}
Compared with procedure-oriented programming, object-oriented programming is a new thought, and not easy to be accepted and understood by students. This paper introduces the basic thought of procedure-oriented and object-oriented programming, discusses the differences of them. Combined with teaching contents and characteristics of Java language, guides students to complete the way of thinking transition from procedure-oriented to object-oriented, and finally expounds the establishment process of object-oriented programming thought, the effect which the students mastered is good.
\end{abstract}

Keywords-Procedure-oriented; object-oriented; way of thinking; transition

\section{INTRODUCTION}

"Programming" is the core course of computer specialty in Colleges and universities; its teaching goal is to make students master the idea and method of programming, as well as the basic programming process and skills[1]. Compared with procedure-oriented programming, object-oriented programming is a new programming thought, and not easy to be accepted and understood by students. How to stimulate students' interest and realize the way of thinking transition from the procedure-oriented to the object-oriented has become the primary problem to be solved in the teaching of objectoriented courses[2].Take the case of Java language, and combined with teaching practice, guides students to understand and master the new thought \& technology other than procedure-oriented programming, especially emphases on the establishment process of object-oriented programming thought.

\section{WORK RELATED}

Program design method is divided into Procedure-Oriented and Object-Oriented (Oriented. the way of thinking transition from procedure-oriented to object-oriented, is an urgent problem to be solved in teaching.

\section{A. Basic Thought of Procedure-oriented}

Procedure-oriented adopts the process-oriented approach to design structured programming, It is a kind of methods of mathematical thinking or computer thinking, is different from methods are used when people understand the world. The core of Procedure-oriented is functional decomposition; a complicated problem is broken into the combination of some simple problems, namely "from top to bottom, step by step". For each simple problem, designs algorithm with the data as the center and around the function of the realization, forms the entire program, such a program contains a main module and a lot of sub modules. As shown in Figure 1

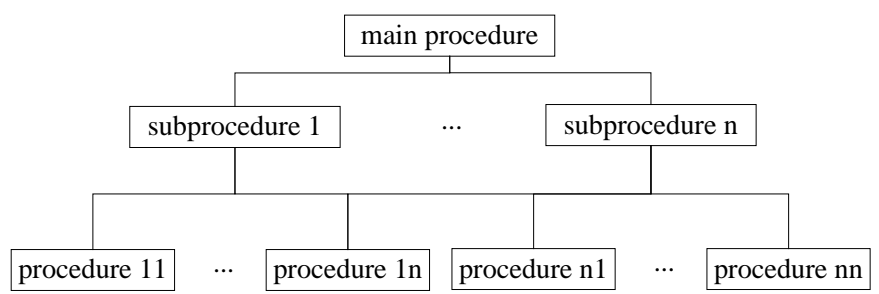

Fig. 1. Structured program.

\section{B. Basic Thought of Object-oriented}

Object-Oriented Programming is to use human thinking to recognize, understand and describe things in real life that is relationships between objects and objects in the program system can reflect things that are inherent in the problem domain and their relationships.

The essence of Object-Oriented programming is to encapsulate data and operation together, and form a class. Class is an abstract description of object features. Data members are used to describe the properties of an object, Data functions are used to describe the behavior of an object, through the same or different classes to communicate with each other and to solve the problem. Therefore, in the Object-Oriented programming, the program is designed as a set of mutually cooperative objects, rather than a set of mutually cooperative function $[4,5]$ The main idea is that the data (data members) and the corresponding function of these data (member functions) are encapsulated in a Class, and the use of the data variables are called Object, as shown in Figure 2.

\section{Difference between Procedure Oriented Programming (POP) \& Object Oriented Programming (OOP)}

This paper discusses Basic thought of Procedure-oriented and Object-oriented in the last two sections, there are many differences between them. As shown in table I: 


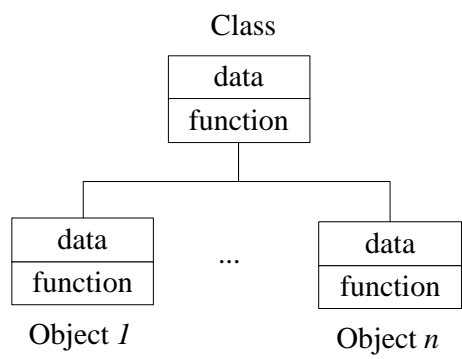

Fig. 2. The essence of Object-Oriented programming

TABLE I. DIFFERENCES BETWEEN POP \& OOP

\begin{tabular}{|c|c|c|}
\hline & $\begin{array}{c}\text { Procedure Oriented } \\
\text { Programming } \\
\end{array}$ & $\begin{array}{c}\begin{array}{c}\text { Object Oriented } \\
\text { Programming }\end{array} \\
\end{array}$ \\
\hline Divided Into & $\begin{array}{l}\text { program is divided into } \\
\text { small parts } \\
\text { called functions. }\end{array}$ & $\begin{array}{l}\text { program is divided into } \\
\text { parts called objects. }\end{array}$ \\
\hline Data Moving & $\begin{array}{l}\text { Data can move freely from } \\
\text { function to function in the } \\
\text { system. }\end{array}$ & $\begin{array}{l}\text { objects can move and } \\
\text { communicate with each } \\
\text { other through member } \\
\text { functions. }\end{array}$ \\
\hline Approach & $\begin{array}{l}\text { follows Top Down } \\
\text { approach. }\end{array}$ & $\begin{array}{l}\text { follows Bottom Up } \\
\text { approach. }\end{array}$ \\
\hline Overloading & $\begin{array}{l}\text { Overloading is not } \\
\text { possible. }\end{array}$ & $\begin{array}{l}\text { overloading is possible in } \\
\text { the form of Function } \\
\text { Overloading and Operator } \\
\text { Overloading. }\end{array}$ \\
\hline $\begin{array}{l}\text { Access } \\
\text { Specifiers }\end{array}$ & $\begin{array}{l}\text { does not have any access } \\
\text { specifier. }\end{array}$ & $\begin{array}{l}\text { has access specifiers } \\
\text { named Public, Private, } \\
\text { Protected, etc. }\end{array}$ \\
\hline Importance & $\begin{array}{l}\text { Importance is not given } \\
\text { to data but to functions as } \\
\text { well assequence of actions } \\
\text { to be done. }\end{array}$ & $\begin{array}{l}\text { Importance is given to the } \\
\text { data rather than procedures } \\
\text { or functions because it } \\
\text { works as a real world. }\end{array}$ \\
\hline Expansion & $\begin{array}{l}\text { To add new data and } \\
\text { function is not so easy. }\end{array}$ & $\begin{array}{l}\text { provides an easy way to } \\
\text { add new data and function. }\end{array}$ \\
\hline Data Access & $\begin{array}{l}\text { Most function uses Global } \\
\text { data for sharing that can be } \\
\text { accessed freely from } \\
\text { function to function in the } \\
\text { system. }\end{array}$ & $\begin{array}{l}\text { data can not move easily } \\
\text { from function to function, } \\
\text { it can be kept public or } \\
\text { private so we can control } \\
\text { the access of data. }\end{array}$ \\
\hline Data Hiding & $\begin{array}{l}\text { does not have any proper } \\
\text { way for hiding data so it } \\
\text { is less secure. }\end{array}$ & $\begin{array}{l}\text { provides Data Hiding so } \\
\text { provides more security. }\end{array}$ \\
\hline Examples & $\begin{array}{l}\text { Example : C, VB, } \\
\text { FORTRAN, Pascal. }\end{array}$ & $\begin{array}{l}\text { Example: C++, JAVA, } \\
\text { VB.NET, C\#.NET. }\end{array}$ \\
\hline
\end{tabular}

D. The Way of Thinking Transition from Procedure-oriented to Object-oriented

When we learn the courses of Programming, the university is generally Procedure-oriented language, such as C language program. The thinking way of Procedure-oriented follows the "step of analyzing", which is consistent with the students' mathematical thinking, and is easy to understand and master. But object-oriented is more high level of abstract thinking, namely a transaction problem was decomposed into several objects, the purpose of object is not in order to complete a step, but in order to describe the behavior of a certain thing in the steps of problem. This kind of thinking is more in line with people's way of thinking and the real world, mainly using the concept of class and object, make the project structure clear, and the program is easy to maintain, enhance code reusability.
The key of thinking transition from procedure-oriented to object-oriented is the establishment of thinking mode, which is "everything is object". The so-called "object", refers to the problem to be treated as a distinct characteristic of the entity. Therefore, when we analysis problems using object-oriented programming, we fully realizes that "the program is composed of class". In the teaching process, we should pay attention to cultivate students' thinking mode, strengthen the basic programming methods and skills training, and guide students to establish the thought of object-oriented programming [7].

\section{CONSTRUCTION THINKING WAY OF OBJECT-ORIENTED}

In the teaching process, teachers must follow the students' cognition law, in accordance with easy to difficult, image to abstraction, design teaching cases, which help students to complete the thinking transition from the Procedure-oriented to the object-oriented.

\section{A. To Use Old Knowledge Lead to New Concept}

"When people know a kind of new things, always use the original schema assimilation, if successful, will be the balance of understanding, otherwise will be alienated, adjust the original schema or create a new schema, until a new equilibrium is reached[3].", therefore, teachers should follow the law of cognition and expand the new concept based on the knowledge that students have already had.

Design case: review structure of procedure-oriented to introduce "class" of object-oriented, Structure is a kind of structural type, which reflects the integration of data from one another to a whole, only static data aggregation, no action description, in teaching process, at this time, introduce "class" of object-oriented, which include data members (static) and the operation of data (dynamic). For example, the structure pet will be extended to class pet, in structure pet, can only represent the pet's data: pet name, type and other static description, but in class pet, you can also have a dynamic description to eat, drink, etc.. The conversion process of from the structure to the class as shown in figure 3 :

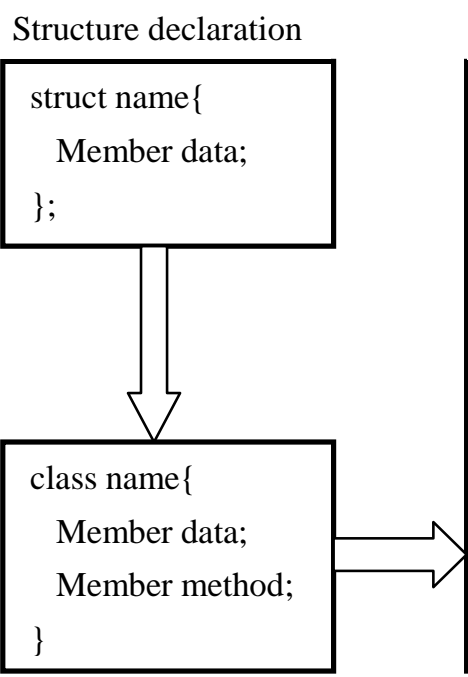

class declaration

class name \{

public:

Member data;

Member method; protected:

Member data;

Member method; private:

Member data;

Member method;

Fig. 3. The conversion process of from structure to class 


\section{B. To Use Image Lead to Abstraction}

From image thinking to abstract thinking is a inevitable process of the development of thinking. In the abstract thinking is always based on the image intuitive thinking, through the image way of thinking, to make the abstract problem specific and intuitive, so as to find the way to solve the problem.

Case design: use a real-life object as an example; introduce the parent class (pet) and subclass (dogs, cats) intuitively and vividly. Through the case, expounds three basic characteristics of the object: encapsulation, inheritance, and polymorphism. For example, the statement of class pet, class cat, class dog, three feature of the classes shown in Figure 4:
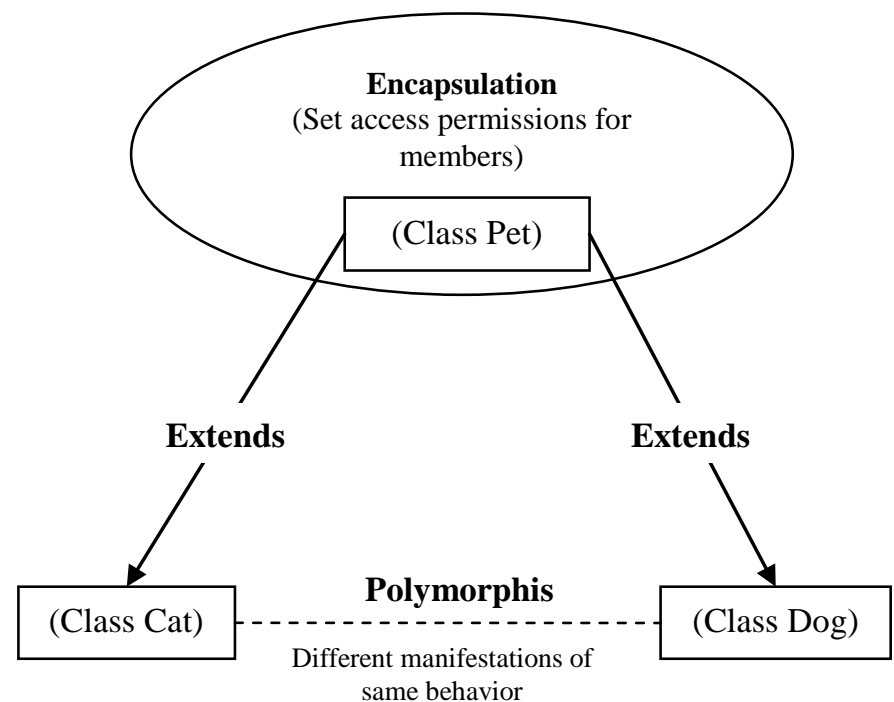

Fig. 4. Encapsulation, inheritance, polymorphism of Class

Step 1: define the image class Dog; class Cat, the class diagram as shown in figure 5 :

\begin{tabular}{|l|}
\hline \multicolumn{1}{|c|}{ Dog } \\
\hline - name:String \\
- health:int \\
- love:int \\
- strain:String \\
\hline + eat():void \\
+ Dog()
\end{tabular}

\begin{tabular}{|l|}
\hline \multicolumn{1}{|c|}{ Cat } \\
\hline - name:String \\
- health:int \\
- love:int \\
- sex:String \\
\hline +eat():void \\
+ Cat()
\end{tabular}

Fig. 5. Class diagram of Class Dog and Class Cat

From Figure 5 we can see that two classes have a lot of duplicated code (attributes: name, health, love and methods: eat ()), we can try to abstract the repeat code, define a new class of Pet, so this new kind of Pet is called a parent class, It follows that class pet, the class Dog and class Cat is the father-son relationship, namely inheritance. Inheritance is the process of using an existing class to create a new class, the existing class called the parent class, a new class called subclass.
Step 2: define the abstract class Pet. The repeated code of the class Dog and the class Cat will be extracted combined into the parent class Pet, the class diagram as shown in figure 6:

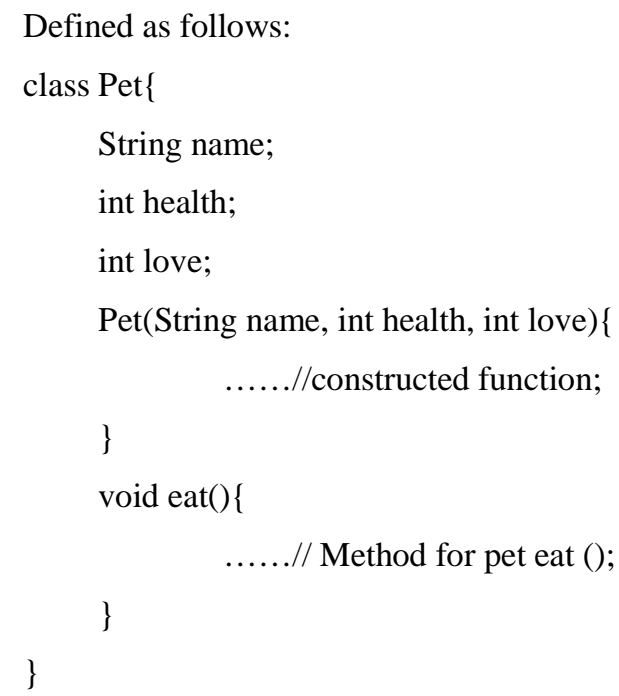

Next, we define a pet object based on the Pet class:

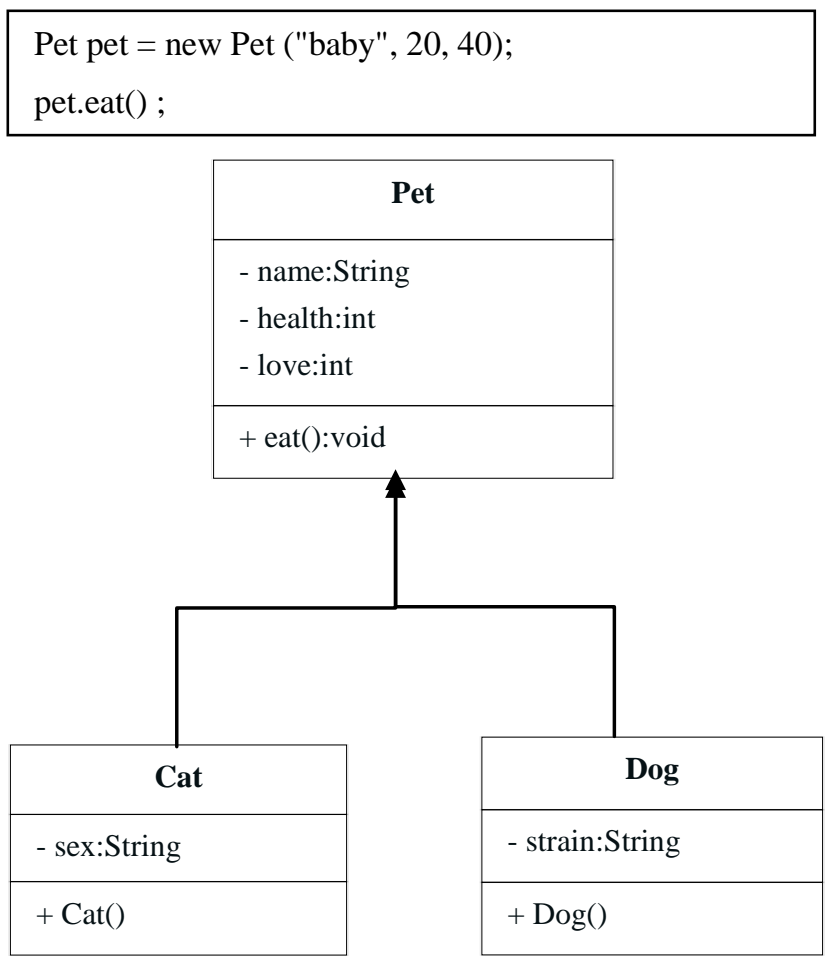

Fig. 6. Class diagram of Class Pet, Class Dog and Class Cat

The above statement is to define an object pet of class Pet, pet is the general name of a lot of specific animals, when we need to adopt pet instances, a cat or a dog can be adopted and other specific kinds of instances could not get the instance of pet. So, at this time, teachers introduce the concept of abstract class to students: an abstract class is often used to represent the problem domain, and to draw abstraction from analysis and design, a series of looks different, but essentially the same 
abstract concepts concrete. The parent class Pet is abstract, subclass Dog, subclass Cat is specific, defined as follows:

abstract class Pet \{\}

class Dog extends Pet \{\}

class Cat extends Pet \{\}

Step 3: realization of polymorphism

if class Dog and class Cat inherit eat () method from parent class Pet, then the result of the execution is the same as what they eat, in fact, dog eat bones, cat eat fishes, obviously, different subclasses need to get different results when executed in the same manner, then we need use polymorphism. In a subclass, defined names, parameters and return values are related to the type of parent class in the same manner to cover the parent class method to achieve polymorphism performance method calls. In the following statements, different subclass object call eats () method, performing eat () method which was rewritten eat () of parent class; get different operating results. This is a concrete manifestation of polymorphism. Specific implementation is as follows:

public abstract class Pet $\{$ // abstract class -parent class Pet public abstract void eat()\{\}

\}

public class Dog extends Pet\{ // specific class-subclass Dog // subclass Dog rewritten eat() of parent Class Pet public abstract void eat( $)\{$

System.out.println(“dog eat bones”); \}

\section{\}}

public class Cat extends Pet $\{$ // specific class-subclass Cat

// subclass Cat rewritten eat() of parent Class Pet public abstract void eat()\{

System.out.println(“cat eat fishes”);

\}

\}

When we execute the following statements, we will get different results;

Pet pet;

pet=new $\operatorname{Dog}()$;

pet.eat(); // execution result: dog eat bones

pet=new $\operatorname{Cat}()$;

pet.eat(); // execution result: cat eat fishes

\section{CONCLUSION}

Procedure-oriented and object-oriented are two different ways of thinking, the procedure-oriented programming is a set of functions, and the object-oriented programming is a collection of classes $[8,9]$. In the object-oriented programming teaching process, we need to make students clearly understand the concepts and relationship between object and class get rid of Procedure-oriented programming method to learn the objectoriented thinking. Therefore, when we teach students who had mastered C programming skills, the emphasis of teaching should be defined as the technology of object-oriented program. Follow the students' cognitive law, elaborate design teaching case, guides students to complete the way of thinking transition from procedure-oriented to object-oriented step by step.

\section{ACKNOWLEDGMENT}

Yi Wang, HuiTing Wu and Min Sun are thanked for helpful review comments and to YuDa Chen for editorial handling and thoughtful suggestions, which have helped to improve this article. The research is supported by Hubei Provincial Department of Education (Grant No. 2013455), Chutian College Huazhong Agricultural University (Grant No. 201303 and 201301).

\section{REFERENCES}

[1] Q He, H Yan, X Su, et al. Implementing Scheme of Programming Foundation Course, China University Teaching. 2010(5) pp.62-65. (In Chinese)

[2] J Su,W Y Weng. Teaching practice and thinking of Java programming teaching, Computer Education 2014(24): pp.147-149. (In Chinese)

[3] Jerome S B. Education process. Beijing: culture and Education Press.1982: pp.28-31. (In Chinese)

[4] Y M Liu, Teaching research and reform on Java course group based on the ability of "practice and innovation", Computer Education, 2015(14),pp.35-40. (In Chinese)

[5] M Li, H Wen, M Du, Teaching Reform of Programming Courses based Subject Competition, Computer Education, 2014(13),pp.72-74. (In Chinese)

[6] L Liu. Establish a Practical Teaching System, Cultivate Students Innovation Ability, Education and Vocation,2013(32).pp.164-165. (In Chinese)

[7] L Tang, T Li, D Xiao. Design of Java Practical Course Teaching Based on Flipped Classroom. Computer Education,2015(4).pp.103-106. (In Chinese)

[8] D M Lin, H Gu. Comprehension and Visual Representation Algorithm of Object-oriented Program. Computer Engineering,vol 38,2012,pp.7277. (In Chinese)

[9] Karahasanovic A, Levine A K, Thomas R. Comprehension Strategies and Difficulties in Maintaining Object-oriented Systems: An Explorative Study. Journal of Systems and Software,vol 80,2007,80, pp.1541-1559. 